\title{
Study on the performance of air conditioning system combining heat pipe and vapor compression based on ground source energy-bus for commercial buildings in north China
}

\author{
Yijun Gao, Wei Wu, Zongwei Han, Xianting Li* \\ Tsinghua University, Beijing, China \\ * Xianting Li. Tel: +86 01062785860, Fax: +86 01062785860, E-mail: gaoyj08@mails.tsinghua.edu.cn
}

\begin{abstract}
After introducing the application status and problems of geothermal air conditioning system in China, a new kind of ground source air-conditioning system (EBCS) is put forward. The system consists of distributed air-conditioners combining heat pipe and vapor compression, fresh air handling unit with large enthalpy difference and ground source water loop. Geothermal energy is transported to the combined air-conditioners for heating and cooling by water loop. The combined air-conditioner can be operated at heat pump condition or heat pipe condition for air conditioning. In winter and transition season, the cooling energy in ground can be directly used for the cooling in inner zone by heat pipe mode, while the recovered heat is used for heating in peripheral zone.

To analyze the performance of proposed system, a commercial building in north China has been taken as the research object, and the annual energy use is simulated. It is shown that the new system can save $21.7 \%$ energy compared to the traditional ground source heat pump system, and may be a potential air conditioning system for commercial buildings in north China.
\end{abstract}

Keywords: Building energy efficiency, Ground source, Heat pipe, Water loop, fresh air handing unit, air conditioning.

\section{Introduction}

The ground source heat pumps (GSHP) are widely used in China. The building areas that use this system exceed $10,000,000 \mathrm{~m}^{2}$ in 2008 , and it continues to keep a rapid growth ${ }^{[1]}$. The ground source heat pump is a heating and air-conditioning system which uses the shallow geothermal energy on the surface of the earth. The shallow geothermal energy is regarded as a renewable energy source ${ }^{[2]}$. In summer, the soil temperature is lower than the ambient temperature, which contributes to improve the COP of heat pumps. At the same time, the waste heat of buildings in summer can be stored in the soil to supply heat in winter. Thus, heat is transferred over seasons. The waste building heat rejected in summer and the primary energy demands for heating in winter are decreased greatly, which is good for environment protection. However, the COPs, especially the cooling COPs of many GSHP projects in China are proved to be not higher, or even lower than that of the traditional water-cooled systems with cooling towers. The existing problems in the GSHP systems are analysed and a novel central air conditioning system using geothermal energy is put forward.

\section{Analysis on the existing problems in traditional GSHP systems}

The traditional GSHP system consists of cooling water pumps, underground heat exchanger, heat pump unit, chilled and hot water pumps and terminal fan-coil units. The GSHP produces chilled water in summer and hot water in winter which is then transported to terminal fan-coil units to realize cooling and heating. At the same time, cooling water, the heat and cold source of the GSHP unit, is transported through underground heat exchanger. In this way, the ultimate energy transfer of the system is realized.

The main problems of traditional GSHP systems are listed as follows: 
1) The centralized producing chilled water and hot water in summer and winter increases the energy transfer links of systems. So the improvement of COP is restricted. Besides, it is very common that the COP of heat pump is low under partial load, which leads to huge energy use.

2) In order to transport chilled water and hot water, the energy use of water circulating pumps of GSHP system is very high.

3) In the existing GSHP systems, usually, the switch of cooling and heating is realized by switching the cooling water circulation. The control is difficult because of the complexity of cooling water systems. In winter and transition season, when the cooling and heating is demanded simultaneously, it needs to produce both chilled and hot water.

How to improve the COP of GSHP systems? Based on the analysis above, some factors below should be taken into consideration.

Firstly, the centralized chilled and hot water should be cancelled. Cold or heat in cooling water can be transferred to the room air directly by distributed terminal cooling and heating units. So the energy transfer links are reduced, and the chilled and hot water pumps are cancelled. Consequently, the energy use of water pumps is reduced. On the other hand, the advantage of flexible adjustment of distributed terminal units can improve the cooling and heating COP under partial load.

Secondly, make the best use of the low temperature advantage of geothermal energy. The shallow soil temperature is lower than the demanded room temperature most of the year. So, it will obviously reduce the cooling energy use of a compressor if the temperature difference is used for natural cooling. But the system must be able to flexibly switch between natural cooling and compression refrigeration. When the natural cooling mode cannot meet the demand, it can easily be changed to compression mode.

\section{Introduction of the new energy-bus air conditioning system}

A new energy-bus central air conditioning system (EBCS) based on ground source is proposed according to the analysis above.

\subsection{Composition construction and key equipments of EBCS}

The new system, which is put forward by Xianting Li et al ${ }^{[3]}$, professor of Tsinghua University, consists of water loop, water-cooled air conditioners combined with heat pipe, and fresh air handling unit with large enthalpy difference. The cooling water is transported to the terminal air-conditioners combined with heat pipe and fresh air handing units for heating, cooling by the water loop. The terminal air-conditioners combined with heat pipe can realize natural cooling in heat pipe mode or vapour compression cycle in heat pump mode depending on the water loop temperature. The fresh air handing unit with large enthalpy difference has a strong ability of dehumidification, which makes it capable of carrying much more building latent heat load in summer. The key equipments are introduced as follows.

\section{Cooling-only type terminal unit with natural cooling function}

The schematic diagram is showed as Figure 1. It combines the compression refrigeration circulation and separated heat pipe technique, which can realize switching between the two operating modes. When there is a temperature difference between the water loop and the room air, the compressor can stop working and the heat pipe starts to operate natural cooling circulation. When the water loop temperature is higher than the room air temperature, the 
vapour compression refrigeration mode is activated. This unit is suitable for buildings with inner zones that need cooling throughout a year.

\section{Heat pump type terminal unit with natural cooling function}

The schematic diagram is showed as Figure 2. Compared to the cooling-only type unit, there is an additional four-way valve in heat pump type unit. Thus, the compressor is able to produce heating. So this unit can meet the demand of cooling as well as heating in the peripheral zones all year round.

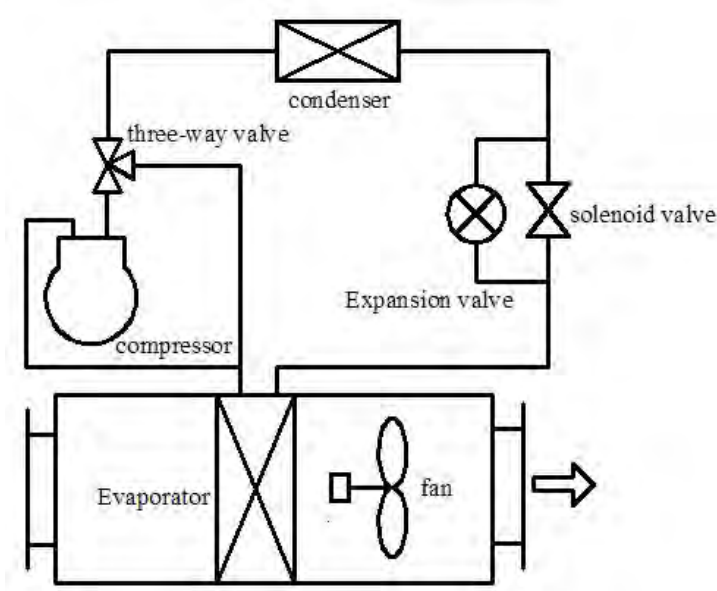

Figure 1 Cooling-only type terminal unit with natural cooling used in inner zone

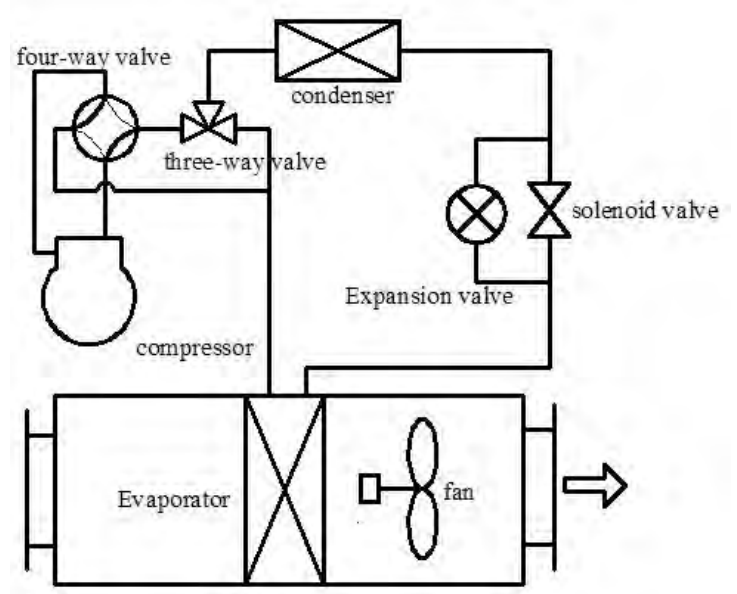

Figure 2 Heat pump type terminal unit with natural cooling used in peripheral zone

\section{Direct evaporative fresh air handing unit with large enthalpy difference}

The schematic diagram of direct evaporative fresh air handing unit with large enthalpy difference is showed as Figure 3. With the sensible heat exchanger, this unit can realize the sensible heat exchange between the fresh air handled by evaporator or condenser and nonhandled fresh air. So the fresh air can be pre-cooled and the refrigeration system mainly carry the latent heating load in summer, which consequently reduces the energy use of the fresh air handling system. In winter, the non- handled fresh air can be pre-heated by the handled hot fresh air so as to solve the problem that compressor cannot work because of too low condensation pressure. It makes sure that the system can still work normally in cold weather.

Compared with the traditional fresh air unit, the fresh air handing unit with large enthalpy difference has a strong ability of dehumidification. So the fresh air handling unit is used to carry the latent load while the heat pipe combined air-conditioner is used to undertake the sensible heat load. 


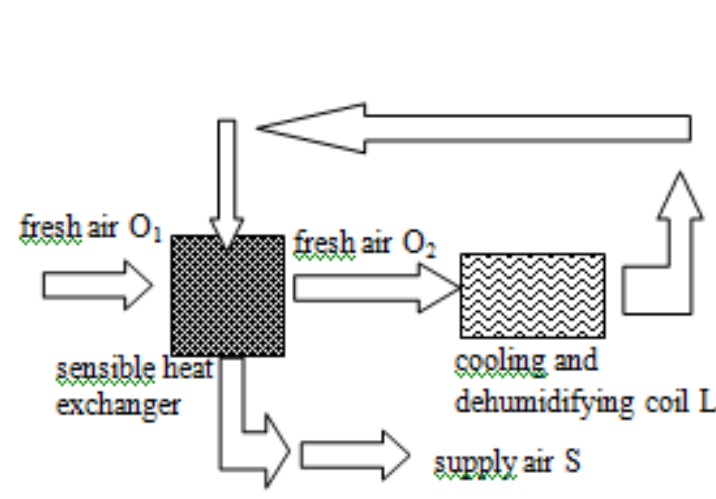

(a)

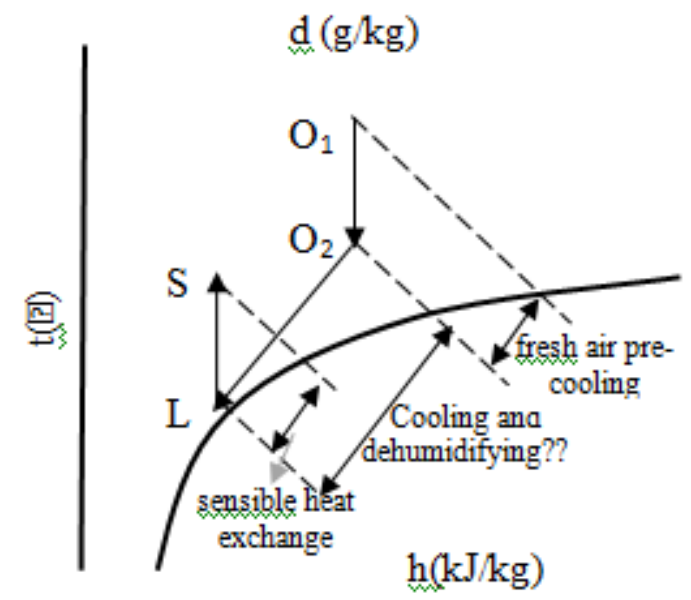

(b)

Figure 3 Direct evaporative fresh air handing unit with large enthalpy difference the schematic diagram (b) the psychrometric chart of air handling process notes : $O_{1}$ is the outdoor air condition, $S$ is supply air condition Example in chart has no dehumidifying

\subsection{The working principals of EBCS}

In cooling season, the water-cooled air conditioners combined with heat pipe can realize switch between heat pipe mode (natural cooling) and air conditioning mode. At the beginning of cooling season, the soil temperature is low and the building load is small. So the terminal units can completely provide natural cooling under heat pipe mode. The heat is released to water loop and then stored in the soil through underground heat exchanger. When the heat pipe mode is insufficient to meet the cooling demand and the room temperature is higher than the maximum set value, the air conditioning mode is activated. When the room temperature is lower than the minimum set value, the compressor stops working and the heat pipe mode is activated. The switch between two operating modes can greatly reduce the compressor's working time.

In winter, the natural circulation of heat pipe mode is operated for cooling in the inner zones while the heat pump mode is operated for heating in the peripheral zones. If there is an unbalance between heat released to the soil and absorbed from it, heat compensation is needed. So this system can also recover the waste heat of inner zones for heating.

\section{Energy saving and economic analysis of the new system}

In order to evaluate the energy saving potential of the new system, a building model is built to simulate the annual energy consumption of the system which starts to operate from the summer cooling term. And then the energy use of the EBCS system and a traditional GSHP system are compared. Beijing, with a year average temperature of $11.4{ }^{\circ} \mathrm{C}$, is chosen as the simulation city. Both the EBCS and traditional GSHP system use underground heat exchangers as cold and heat source.

\subsection{Building model}

The building model is obtained from a research office building in Beijing after suitable simplification. There are 5 floors, and the drawing of standard floor is showed as Figure 4. 


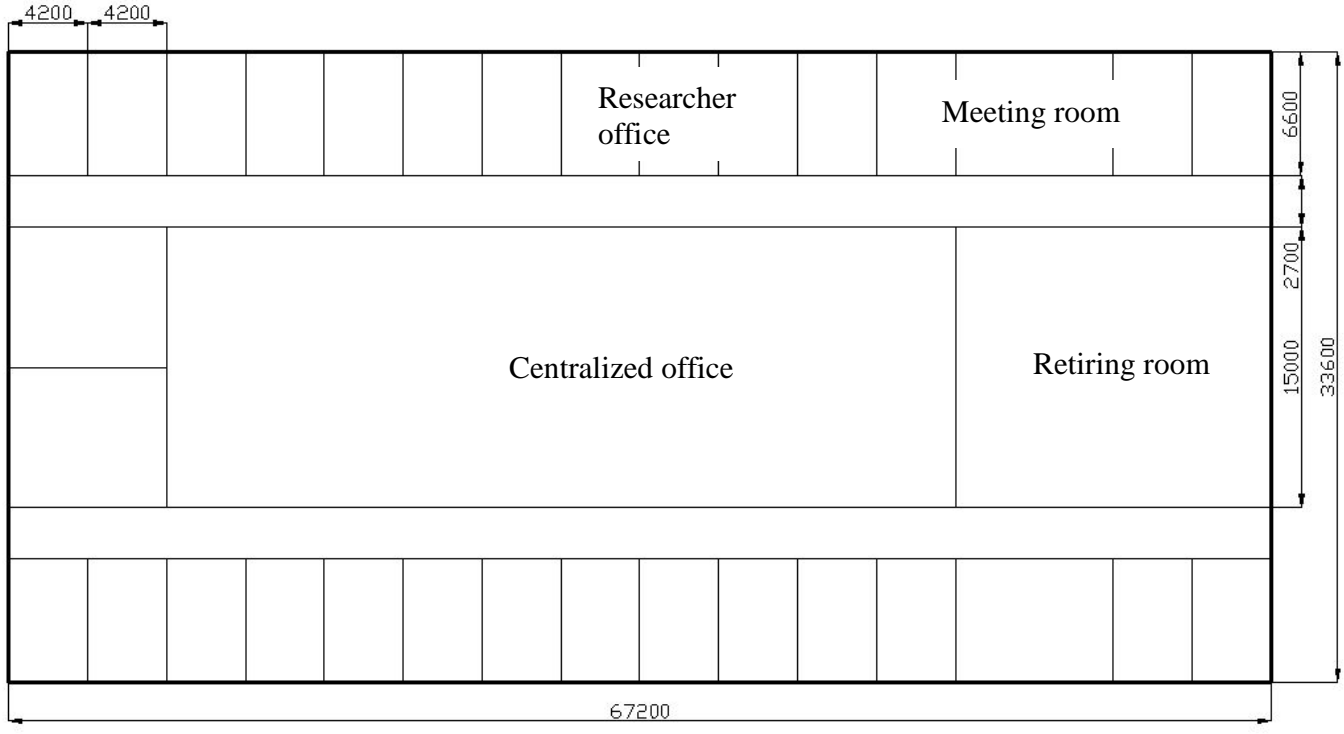

Figure 4 Standard floor of the building model

The area of each floor is $2258 \mathrm{~m}^{2}$ and the total building area is $11290 \mathrm{~m}^{2}$. The heat transfer coefficient of outside wall and roof is $0.8 \mathrm{~W} / \mathrm{m}^{2} \cdot \mathrm{K}$. The windows are doble-glazed with a 12 $\mathrm{mm}$ air layer and its heat transfer coefficient is $3.9 \mathrm{~W} / \mathrm{m}^{2} \cdot \mathrm{K}$. The shading coefficient of the window is 0.83 and the inner shading is used. The window-wall area ratio is 0.65 in the south and north side and 0.9 in the east and west side.

The average minimum fresh air flow rate for each person in the building is $30 \mathrm{~m}^{3} / \mathrm{h}$. The room temperature is set within $24 \sim 26^{\circ} \mathrm{C}$ in summer and $20 \sim 24^{\circ} \mathrm{C}$ in winter. The software DEST-C is used to calculate the whole year hourly building load ${ }^{[4]}$. The calculation results are showed as Table 1 and Table 2.

Table 1 The total building load

\begin{tabular}{cc}
\hline & Load \\
\hline peak heating load & $730.4(\mathrm{~kW})$ \\
peak cooling load & $895.3(\mathrm{~kW})$ \\
annual accumulated heating load & $787.4(\mathrm{MWh})$ \\
annual accumulated cooling load & $844.3(\mathrm{MWh})$
\end{tabular}

Table 2 The peak load of typical room

\begin{tabular}{cccccc}
\hline Typical room & area $\left(\mathrm{m}^{2}\right)$ & $\begin{array}{c}\text { peak room cooling } \\
\text { load }(\mathrm{kW})\end{array}$ & $\begin{array}{c}\text { fresh air cooling } \\
\text { load }(\mathrm{kW})\end{array}$ & $\begin{array}{c}\text { peak room } \\
\text { heating load } \\
(\mathrm{kW})\end{array}$ & $\begin{array}{c}\text { fresh air } \\
\text { heating load } \\
(\mathrm{kW})\end{array}$ \\
\hline $\begin{array}{c}\text { centralized } \\
\text { office in } \\
\text { inner zone } \\
\text { office in }\end{array}$ & 630.00 & 52.68 & 29.29 & -4.90 & 29.17 \\
outer zone & 27.70 & 1.75 & 0.93 & 2.05 & 0.66 \\
\hline
\end{tabular}

Notes: the humidification load is not included. 


\subsection{Simulation method for the energy use}

The GSHP unit, fan-coil unit, fresh air handling unit, air conditioners combined with heat pipe and circulation water pump are chosen based on the total building load and peak cooling and heating load of typical room. The underground heat exchanger is designed to have 105 pipes with a $5.5 \mathrm{~m}$ interval and an $80 \mathrm{~m}$ depth. The U-bend heat exchanger is used in the simulation. Usually, the average transferring heat per unit of borehole depth is about $56 \mathrm{w} / \mathrm{m}$ in Beijing. The U-bend is regarded to be equivalent to a vertical single pipe, and is numerically discreted by the inner node control volume method ${ }^{[5]}$.

The method to calculate the energy use of GSHP unit or air conditioners combined with heat pipe is as follows ${ }^{[6]}[7]$ :

$$
N_{c}=\sum \frac{Q_{c i}}{E E R}+\sum \frac{Q_{h i}}{C O P}
$$

Where $N_{c}$ is the electricity consumption of GSHP unit or air conditioners combined with heat pipe, kWh. $Q_{c i}, Q_{h i}$ is the building cooling load and heating load respectively in hour $\mathrm{i}$, $\mathrm{kWh} . E E R_{i}, C O P_{i}$ is the energy efficiency ratio of GSHP unit/ air conditioners combined with heat pipe unit respectively in hour i.

The method to calculate the energy use of fans is as follows:

The total electricity consumption of fans in each system includes fan consumption in fresh air unit, fan-coil and air conditioners combined with heat pipe unit.

$$
N_{f}=N_{m} \times \tau
$$

Where $N_{m}$ is the rated power of fans which are chosen based on the peak cooling load. $\tau$ is the annual running time of the air-conditioning system.

The method to calculate the electricity consumption of water pumps is as follows:

$$
N_{s}=\sum N_{w} \times n_{i}
$$

Where $N_{w}$ is the rated power of a water pump. 3 chilled water pumps, 3 cooling water pumps and 3 hot water pumps are chosen with 2 in usage and 1 as backup. The selection of pumps is based on the peak cooling and heating load in the whole year. $n_{i}$ is the number of pumps that should run in hour i.

\subsection{The simulation results for annual energy use}

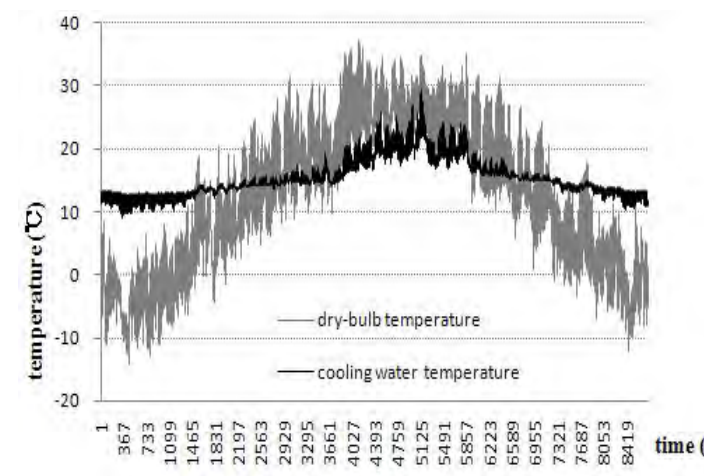

Figure 5 Hourly dry-bulb temperature and cooling water temperature

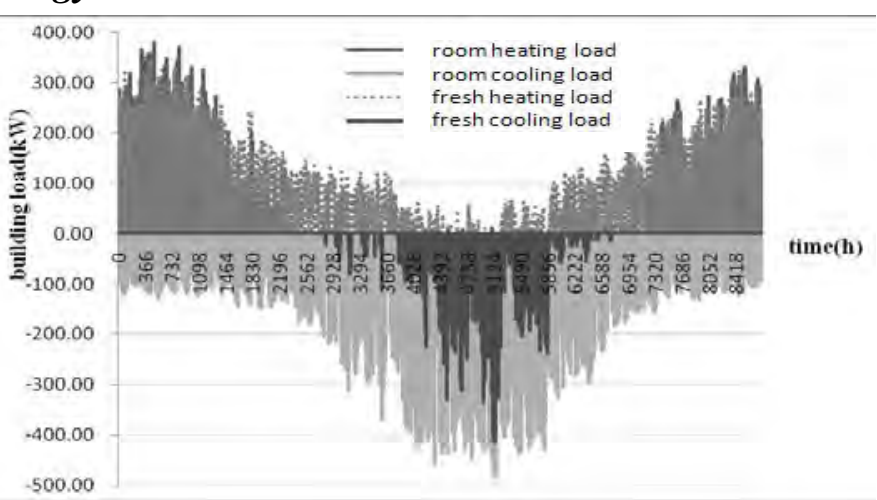

Figure 6 The calculated hourly building load for the whole year 


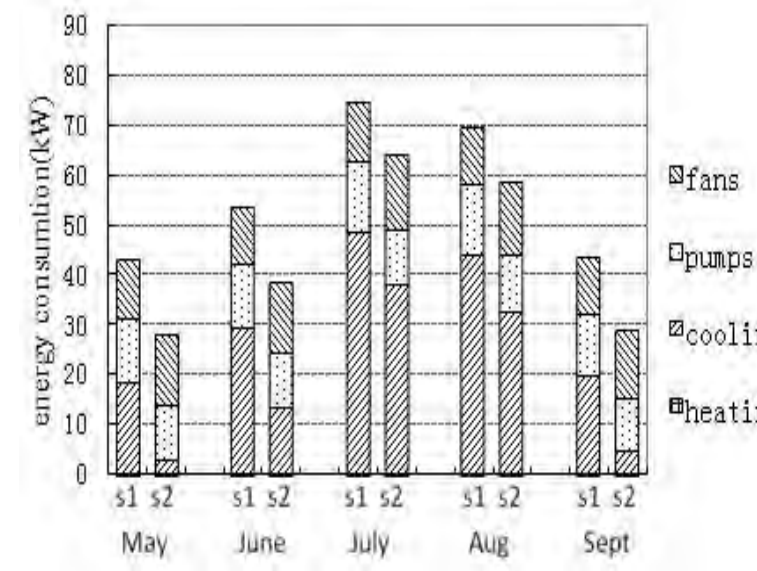

Figure 7 The comparison results of system energy use in summer

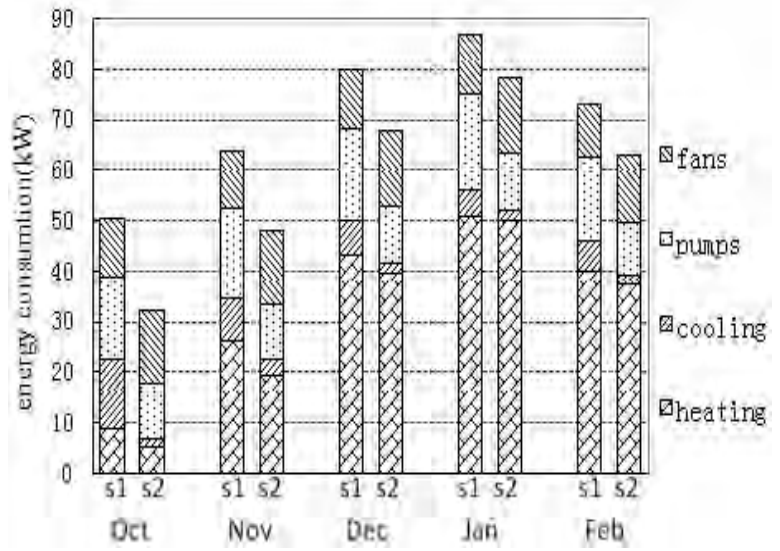

Figure 8 The comparison results of system energy use in winter and transition season

Notes: "s1" represents the GSHP and "s2" represents the EBCS, "heating" is the electricity consumption of compressors and in the GSHP and EBCS for heating, and "cooling" is the electricity consumption of compressors and heat pipe fans in the GSHP and EBCS for cooling.

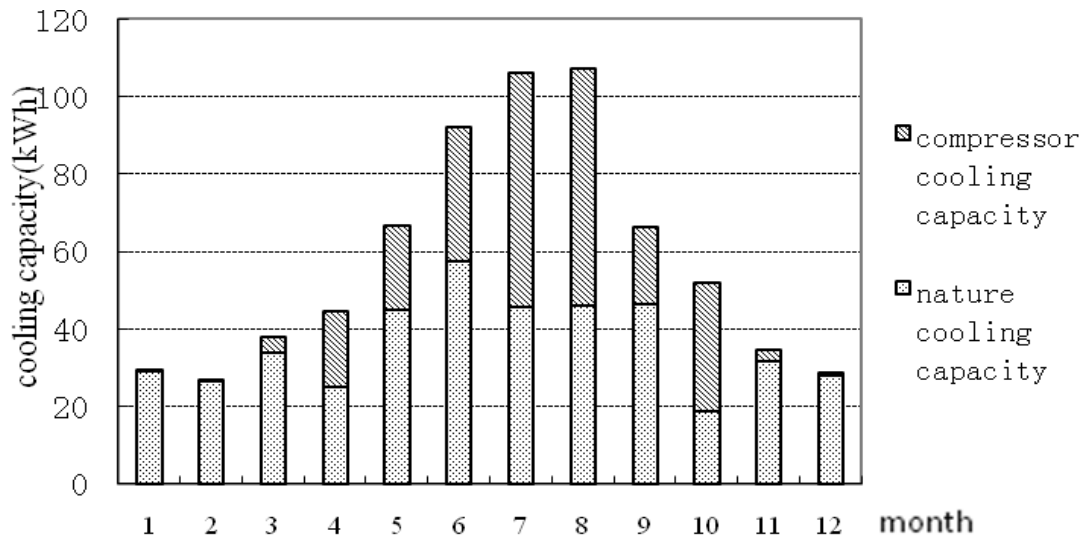

Figure 9 The annual accumulated natural cooling capacity analysis

From the energy use comparison, it can be concluded that:

1) The energy saving potential of EBCS is $21.7 \%$ compared to the traditional GSHP system. In EBCS, the air conditioners combined with heat pipe and water pumps use less energy while the fans use a little more energy.

2) Air conditioners combined with heat pipe contribute the most of energy saving because of natural cooling. With the heat pipe, the natural circulation mode can undertake almost all the cooling load in winter and transition season. Even in summer, it can undertake more than $30 \%$ cooling load. In the whole year, the natural circulation mode undertakes more than $60 \%$ cooling load totally.

3) In heating season, the EBCS has an obvious energy-saving advantage under partial load. It indicates that decentralized heating terminal units have higher energy efficiency at partial load. 
4) Since the chilled and hot water pumps are cancelled in the EBCS, the annual electricity consumption of pumps is $30 \%$ lower in EBCS, even if the water head of pumps are higher than the cooling pump in the GSHP system.

\section{Conclusions}

The existing problems of the traditional GSHP systems are analyzed. A novel central air conditioning system based on ground source is proposed. The new system consists of decentralized terminal air conditioners combined with heat pipe, fresh air handing unit with large enthalpy difference and water loop. The chilled and hot water systems are cancelled. And the cooling water is transported to the terminal air-conditioners and fresh air handing units for heating and cooling by water loop. The air conditioners combined with heat pipe have two operating modes: natural cooling circulation and heat pump mode (compression refrigeration/heating). The air conditioners can switch between these two modes. The fresh air handing unit with large enthalpy difference has a strong ability of dehumidification, so it can be used to undertake the major latent load.

Based on the theoretical analysis, the annual energy consumption of an office building in Beijing is simulated. The calculation results show that EBCS can reduce much energy consumption for cooling compared to the traditional GSHP system. That's because the new system can realize natural circulation which can undertake $60 \%$ of the annual cooling load in the whole building. At the same time, EBCS also has obvious energy saving advantage in heating and transportation (pumps and fans) consumptions. The total energy saving potential in the whole year can reach $21.7 \%$. Besides, the system form is simple and the control is easy. The terminal units can flexibly realize cooling and heating depending on the room demand, the same as the four-pipe type system. All this advantages can better ensure the temperature and humidity comfort all year round with much less energy use.

\section{References}

[1] W. Yang, J. Zhou, W. Xu, and G, Zhang. Current status of ground source heat pump in China. Energ. Policy, vol. 38, 2010: 323-332.

[2] Tao Meng. Yanqing Di, Li Liu, et al. Research of ground heat balance of ground source heat pump. 2009 International Conference on Energy and Environment Technology, 2009: 777-781.

[3] Xianting Li, Yijun Gao, Zongwei Han, et al. A new central air conditioning system combining heat pipe and vapor compression based on energy-bus. HEATING VENTILATING \& AIR CONDITIONING, Vol.41, No.2, 2011: 1-6.

[4] Chen Feng, Deng Yuchun, Xue Zhifeng and Wu Ruhong. Toolpack for building environment simulation. HEATING VENTILATING \& AIR CONDITIONING, Vol.29, No.4, 1999: 58-63.

[5] Zongwei Han, Maoyu Zheng, Fanhong Kong. Simulation research on solar-assisted ground source heat pump heating system with seasonal soil thermal storage in severe cold area. ACTA ENERGIAE SOLARIS SINICA. Vol.29, No.5, 2008: 574-580.

[6] Liu Tianwei, Du Kai. Research on the energy saving of water loop heat pump system applied to office buildings. HEATING VENTILATING \& AIR CONDITIONING, Vol.40, No.3, 2010: 63-67.

[7] Huang Bing,Yang Chang-zhi. Resarch on simulation and economic assessment of ground source heat pump system. FLUID MACHINERY, Vol.38, No.1, 2010: 75-80. 